\title{
Portfolio risk-return analysis: The case of the automotive industry in the Czech
}

\section{Republic}

Florin Aliu

Tomas Bata University in Zlin

Zlin, Crech Republic

aliu@utb.cz.

\section{Drahomira Pavelkova}

Tomas Bata University in Zlin

Zlin, Crech Republic

pavelkova@utb.cr.

\section{Bruce Dehning}

Chapman University

Orange, USA, California

bdehning@chapman.edu

Abstract. Risk has always been the concern of managers and shareholders as a part of decision-making processes. Managers tend to control unsystematic risk mostly while trying to minimize the exposure to systematic (market) risk. The paper aims to assess the risk level and risk-return tradeoffs for the companies operating in Czech automotive industry. A diversification formula and calculation of returns using return-on-equity were employed on the yearly basis from 2005 till 2014. The returns and risk calculations were conducted on the portfolio of auto manufacturers, followed by the portfolio of auto suppliers, while the third one was performed for suppliers and manufacturers taken together. The results of the study show that the average correlation coefficient tends to decrease when we move from manufacturers to suppliers, while increasing when we join manufacturers and suppliers in one portfolio. The highest diversification benefit has been reached in the portfolio of auto suppliers. The highest risk is manifested for the portfolio of manufacturers, while the lowest - in the portfolio of auto suppliers. Risk level declined when we joined manufacturers and suppliers in comparison with risk of manufacturers alone. However, the lowest risk and the highest risk-return tradeoff were achieved in the portfolio of suppliers.

Keywords: portfolio theory, portfolio diversification, risk-return analysis, automotive industry.

JEL Classification: E32, F21, G32 


\section{INTRODUCTION}

The automotive sector has been the core industry and a unique economic phenomenon, which has dominated the whole twentieth century (Maxton \&Wormald, 2004). This industry is also one of the largest manufacturing sectors in the global economy. It generates significant economic benefits for the world's economy and is closely linked to a wide variety of international concerns such as energy consumption, emissions, trade and safety (Nieuwenhuis \& Wells, 2015). The automotive industry in the Czech Republic has been the engine for the inclusive growth of the country, both in terms of economic performance and in terms of labour market. With the annual production of 118 vehicles per 1,000 inhabitants, the automotive sector makes up nearly $25 \%$ of the country's industrial production and exports and contributes approximately 7.4\% of GDP (Kozelský \& Novák, 2015). In 2016, cars were exported for the total amount of $\$ 18.7$ billion and vehicle parts of $\$ 13.5$ billion (OEC, 2016).

The automotive industry is highly sensitive to booms and busts of business cycles, since economic activity in this industry moves in line with the overall business cycle. The world financial crisis of 2008 demonstrated the fragility of the industry as well as its spillover effect which impacted the whole economy. Government intervention in several countries was required since automotive companies were considered too big to fail and also too interconnected to fail (Biesebroeck \& Sturgeon, 2010). Over the last decades, the global automobile industry has undergone far-reaching structural changes. While in the past car companies produced almost the entire vehicle within their production lines, large parts of value added are outsourced today, therefore, a much bigger role today belongs to auto parts' suppliers. This has become possible due to modularization and the design of common underbody platforms. The advantage of this strategy is that it enables car producers benefit from economies of scale as they can build more car models on the same platform, a trend strengthened by recent consolidation in the global car industry.

Investors are concerned with the risk-return tradeoff that the automotive industry generates. To design strategy and build portfolio, the Modern Portfolio Theory (MPT) based on the pioneering work of Markowitz $(1952,1959)$ can be applied. Although it is based on simplifying assumptions, it can be successfully used in portfolio analysis for explaining the relationship between return and risk of individual portfolio components. The Capital Market Theory, which is closely related to the MPT, then came up with the Capital Asset Pricing Model (CAPM), which extended the existing theory by an equilibrium view on the asset market. The model is based on the equilibrium between risk and return, where risk brings the investor the highest return at a given level of risk, or the lowest level of risk at a given level of return. Markowitz theory lies within the efficient market hypothesis, which states that markets adjust their own excesses and deviations from the mean are random (Fama, 1968a; 1968b). Investors attempt to keep in their portfolio those securities that are less correlated or negatively correlated. Less correlated assets reduce portfolio exposure to risk. Risk is multidimensional in nature and stands as a daily concern of managers, employees, stakeholders, governments etc. Standard theories of portfolio management consider that risky investments are compensated with higher returns. Financiers are primarily interested in future cash flows that securities will generate. Uncertainties caused from the instability of returns are the main concern in portfolio management. Our work aims to measure the risk level of the automotive industry from the investor's point of view, through a correlation-based method. Holding a diversified portfolio, in the long run, tends to reduce portfolio risk (Muhamad et al., 2006). The number of securities in the same portfolio and their correlation coefficients are the crucial elements for designing a well-diversified portfolio (Sentana, 2004; Tang, 2004; Behr et al., 2013; Medo et al., 2009; Drake \& Fabozzi, 2010). The correlation coefficient assesses the shortrun effect within securities, while the co-integration method measures the long-term dependency of assets' return (Alexander 1999, 2008a, 2008b). Moreover, assets might be highly correlated in the short run, but in the long run they can be negatively correlated. 
This paper treats the automotive industry as the market index or indexing portfolio. Previous studies were focused on testing the theories of portfolio optimization through investing in different types of securities (stocks, bonds, currency etc.), different countries and different sectors. Our study tests the theory of portfolio optimization through investing in the same industry. The process of measuring risk has been divided into three sections: auto manufacturers (Portfolio A), auto suppliers (Portfolio B) and suppliers and manufacturers taken together (Portfolio C). Our work is different from the previous ones since it is the first attempt to measure the risk-return perspective for the automotive industry of the Czech Republic. Taking into account the risk issues of the Czech automotive industry, we attempt to provide answers to the following questions: Does the introduction of more assets within the same industry reduce the risk level of the portfolio? What risk-return tradeoff could investors investing to different portfolios of companies within the automotive sector of the Czech Republic deal with?

According to the results, investments in the same sector cannot perfectly diversify risk, but there is still evidence that it was possible to increase risk-return tradeoffs through investing in auto suppliers operating in the Czech Republic during the period of 2005-2014, even though returns of manufacturers in the portfolio were higher. The lowest wealth in comparison with risk was achieved by investment in the portfolio of manufacturers and suppliers taken together.

The remaining parts of this study are structured as follows. The second chapter contains literature review on the theories and evidence concerning portfolio optimization. The methodology used is described in the third chapter while our results are presented in the fourth one. Conclusion and directions for further research to be conducted are in the last section.

\section{THEORETICAL BACKGROUND}

Constructing a portfolio, which gains superior returns in the market, is every day aim of portfolio managers. Risk is linked with the future outcomes, while the future is unpredictable because it is influenced from the choices that are not yet completed (Soros, 2003). Risk in portfolio management is mainly measured through the uncertainties of returns, which in itself involves: correlation coefficients, weights of each security in the portfolio, and the variance of returns. Each of these factors are influential in increasing or reducing portfolio risk. Higher correlation coefficient, higher weights in particular securities, and higher variance of returns raises the exposure of the investors to unsystematic risk. In addition, the Sharpe ratio, widely used performance indicator, is a reflection of the risk-return tradeoff (Sharpe 1964). The capital asset pricing model (CAPM) built by Sharpe (1964) and Lintner (1965) differentiate extent of risk premium above the market risk and the range of the enterprise risk that should be hedged (Ray, 2010).

In contrast, the risk of individual securities is measured through a beta coefficient, which stands for the slope of fitted data on the linear relationship between market return and individual security return (Chen, 2003; Tofalis, 2006). Beta coefficients measure the sensitivity of securities to market movements. Beta tends to be misleading when the market is not an efficient form and stock prices do not reflect all available information. Fernandez (2015) proposes an alternative form of beta coefficients generated from interviews with the managers of the companies, named the qualitative beta.

The portfolio is constructed from different sort of securities while the interaction between them allow better portfolio optimization and risk reduction. Portfolio managers in their daily investment operations are opposed to diversifiable risk (non-systematic risk) and market risk (non-diversifiable risk). Investors tend to benefit from diversification when investing not only within national borders, but also extending the scope of the investment horizon beyond national markets (Khan, 2011). However, the financial crisis of 2008 proved that stock markets are highly correlated, where worldwide diversification no longer provides a 
portfolio optimization advantage. Expansion in the information technology associated with capital flow movements is considered the main explanation for financial globalization.

Initial signals that international markets are correlated came from the stock market crash of 1987. Studies conducted by Dwyer and Hafer, 1988; Eun and Shim;1989; Von Furtsenberg and Joen, 1989; Bertera and Mayer, 1990 confirmed that US stock market, German stock markets and Japanese stock markets were highly correlated in the crisis of 1987. Beside diversification, each security in the portfolio has its own risk. Risk hierarchy starts with common stocks and ends up with cash as the most liquid asset class. Common stocks pretend higher return (capital gains and dividends) while at the same time hold more risk for shareholders in the moment company goes bankrupt. Non-systematic risk is eliminated through the better arrangement of the portfolio securities while market risk is the shock that comes from the market crisis. Systematic shocks are beyond the scope of the managers to control them (Olibe et al. 2007).

Emerging markets have received increased investors' attention, since they offer new opportunities to enhance the portfolio structure.

The number of securities in a portfolio is a crucial element in risk reduction. In addition, a number of studies confirm that a portfolio with more than 50 uncorrelated stocks, fully completes risk reduction in the portfolio (Copp \& Cleary, 1999; Domain et al., 2007). The large number of stocks held in the portfolio of equity funds is unjustified, since a portfolio with 5 to 16 stocks can eliminate unsystematic risk (Evans \& Archer, 1968; Jannings, 1971; Johnson \& Shanon, 1974; Bird \& Tippett, 1986; Statman, 1987; Surz \& Price, 2000; Tang, 2004; Brand \& Gallagher, 2005). A low number of securities within the portfolio delivers a higher correlation coefficient which increases the risk exposure (Tola et al. 2008; De Miguel et al. 2013). Moreover, construction of the optimal portfolio is linked with the risk appetites of the investors, experience and creativity of the portfolio managers. Shukla (2004) confirms that actively managed portfolios tend to experience excess returns when the securities in the portfolio are more concentrated. The securities tend to be more correlated in the bearish markets than in bullish markets (Butler and Joaquin, 2002). Alexander and Dimitriu (2005) tested the viability of the co-integration and correlation methods analyzing securities in the S\&P 500. Their studies confirmed that there is no substantial difference between the correlation and cointegration based methods.

\section{METHODOLOGY}

This study aims at appraising the risk level of the companies operating in the automotive industry in the Czech Republic. The portfolio diversification formula (1) has been used to measure the risk. The first round of risk measurement has been conducted on the auto manufacturers (Portfolio A). The second round of risk appraisal has been realized on the automotive suppliers that operate in the Czech automotive industry (Portfolio B), while the third portfolio was constructed from combination of auto suppliers and auto manufacturers (Portfolio C). Data were collected from the annual financial statements of automotive companies, published on a yearly basis on the Albertina database. Automotive companies in the Czech Republic are not listed on the Prague Stock Market (PSE). Their market prices are unable to be obtained, companies in the automotive industry are non-public companies. Their accounting metrics stand on historical costs (book values). Based on these limitations, a Return on Equity (ROE) has been used as a return indicator. Total assets have been used to define the weights of each company within the industry. A mathematical formula that measures risk, is designed for companies that are publicly traded. Capital gains (stock price movements) are the main elements in measuring the correlation coefficient. In our case, instead of stock prices we have used ROE. ROE is being considered as a performance measure within the riskreturn model. Risk is captured through the volatility of returns, higher variance stands for higher risk and 
vice versa. The results generated from the calculations signify the risk level of three portfolios, based on their variance, standard deviations and correlation coefficients.

$$
\sigma_{k}^{2}=\sum_{i}^{n_{k}} w_{i k}^{2} \sigma_{i k}^{2}+2 \sum_{i}^{n_{k}} \sum_{j \neq i}^{n_{k}} w_{i k} w_{j k} \sigma_{i k} \sigma_{j k} \rho_{i j k}
$$

Formula explanation: $\sigma_{k}^{2}$ of the portfolio in the year $k$ is computed on the sample of $n_{k}$ companies. Index $i$ indicates a company, $j$ is an auxiliary index assuring that covariance is computed on distinct companies, $\omega$-represents weight of each automotive company within the portfolio based on their total assets, $\omega^{2}$ represents weight in square, $\sigma^{2}$ - variance of returns (ROE), $\sigma$ stands for the standard deviation of returns $(\mathrm{ROE})$ while $\varphi(i, j)$ shows the correlation coefficient within returns (ROE) of automotive companies in the portfolio.

The mathematical formula has been employed on the yearly basis from 2005 till 2014. The correlation coefficient has been conducted with all possible combinations of the companies' performance (measured by ROE).

\section{EMPIRICAL RESULTS AND DISCUSSION}

The results capture an analysis of three portfolios: Portfolio A - 10 auto manufacturers, Portfolio B 37 auto suppliers, and Portfolio C - 10 auto manufacturers and 37 auto suppliers, operating in the Czech Republic. Entities within the industry are considered as a whole portfolio. Return and risk of portfolios have been analyzed and relationship between return and risk has been evaluated.

\subsection{Portfolio A (auto manufactures) analysis}

The weighted average return of the auto manufacturers (2005-2014) stands on the level of $16 \%$ while mean return is $15.9 \%$. The average risk based on results of 2005-2014 captured from the formula (1), is $6.3 \%$.

Volatility of returns is computed on the winsorized values $(2.5 \%$ smallest and largest values were replaced by respective 0.025 and 0.975 quantile values) to eliminate influence of outliers.

Table 1 shows risk-return characteristics of manufacturers in Portfolio A on the yearly basis.

Table 1

Risk-return characteristics of Portfolio A

\begin{tabular}{|c|c|c|c|c|}
\hline Year & Mean ROE & Weighted ROE & $\begin{array}{c}\text { Standard deviation of } \\
\text { winsorised (95\%) ROE }\end{array}$ & $\sigma$ \\
\hline 2005 & $16.2 \%$ & $16.6 \%$ & $12.6 \%$ & $5.1 \%$ \\
\hline 2006 & $18.3 \%$ & $18.7 \%$ & $19.2 \%$ & $5.2 \%$ \\
\hline 2007 & $20.6 \%$ & $21.6 \%$ & $21.2 \%$ & $5.4 \%$ \\
\hline 2008 & $10.9 \%$ & $8.4 \%$ & $22.2 \%$ & $6.1 \%$ \\
\hline 2009 & $3.7 \%$ & $2.0 \%$ & $16.3 \%$ & $6.4 \%$ \\
\hline 2010 & $12.0 \%$ & $12.8 \%$ & $14.6 \%$ & $6.5 \%$ \\
\hline 2011 & $20.3 \%$ & $20.7 \%$ & $19.5 \%$ & $6.9 \%$ \\
\hline 2012 & $20.3 \%$ & $21.3 \%$ & $18.3 \%$ & $7.1 \%$ \\
\hline 2013 & $16.0 \%$ & $16.5 \%$ & $13.6 \%$ & $7.2 \%$ \\
\hline 2014 & $20.8 \%$ & $21.3 \%$ & $22.0 \%$ & $7.3 \%$ \\
\hline
\end{tabular}

Source: Authors' results. 
There are 45 correlation coefficients within 10 auto manufacturers, while the average correlation coefficient is $r=0.15$. Correlation coefficient demonstrates that auto manufacturers are not well diversified. The correlation coefficient reveals on which direction the returns in the portfolio are moving. In Portfolio A, $29(64 \%)$ combinations are positively correlated.

The correlation coefficients of manufacturers in Portfolio A are demonstrated in Table 2.

Table 2

The correlation coefficients of companies in Portfolio A

\begin{tabular}{|c|r|r|r|r|r|r|r|r|r|r|}
\hline \multicolumn{1}{|c|}{ ROE } & \multicolumn{1}{|r|}{ Man 1 } & Man 2 & Man 3 & Man 4 & Man 5 & Man 6 & Man 7 & Man 8 & Man 9 & Man 10 \\
\hline Man 1 & 1 & & & & & & & & & \\
\hline Man 2 & 0.489 & 1 & & & & & & & & \\
\hline Man 3 & -0.053 & 0.208 & 1 & & & & & & & \\
\hline Man 4 & -0.232 & -0.743 & -0.335 & 1 & & & & & & \\
\hline Man 5 & 0.199 & -0.369 & 0.663 & 0.286 & 1 & & & & & \\
\hline Man 6 & 0.311 & 0.58 & -0.132 & -0.617 & -0.761 & 1 & & & & \\
\hline Man 7 & 0.631 & 0.437 & 0.181 & -0.043 & 0.146 & 0.167 & & & & \\
\hline Man 8 & 0.805 & 0.285 & 0.392 & -0.251 & 0.512 & 0.208 & 0.628 & & & \\
\hline Man 9 & 0.423 & 0.371 & 0.176 & -0.224 & 0 & 0.363 & 0.797 & 0.447 & & 1 \\
\hline Man 10 & 0.514 & -0.243 & -0.444 & 0.364 & 0.436 & -0.246 & 0.286 & 0.373 & -0.017 & \\
\hline
\end{tabular}

Man 1 - ŠKODA AUTO, 2 - SOR Libchavy, 3 - EKOBUS, 4 - JAWA Moto, 5 - Hyundai Motor Manufacturing Czech,6 - MTX, 7 - AGADOS,8 - Schwarzmüller, 9 - PANAV, 10 - Iveco Czech

Source: Authors' results.

The highest correlation was achieved in the combination of Hyundai and Ekobus $(r=0.663)$ and Agados and Škoda Auto $(r=0.631)$. The highest negative correlation was found between bus manufacturer SOR and motorbike producer JAWA $(r=-0.743)$. The causes of the high negative correlation might be that both companies deliver heterogeneous final outputs, have different level of sensitivity of business cycles (GDP) and operate in the different markets. JAWA is also the company with the most negative number of correlations $(7)$.

Lines in Figure 1 represent development of mean return, the weighted average return and the standard deviation of returns in Portfolio A.

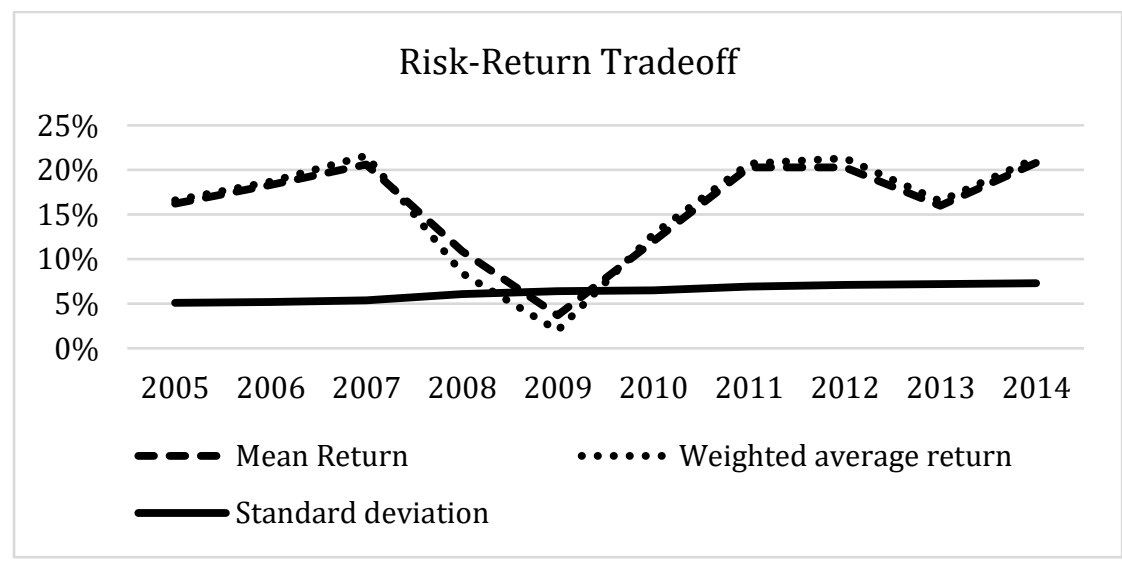

Figure 1. Risk- return tradeoff in Portfolio A

Source: Authors' result. 
In the period of 2005-2014 (except 2009), investors in Portfolio A have been compensated for the risk, since the weighted average return has been higher than the risk level, measured by the standard deviation of the returns $(\sigma)$.

\subsection{Portfolio B (auto suppliers) analysis}

Portfolio B is constructed only from the auto suppliers. 37 companies operating as auto suppliers in the Czech automotive industry were randomly selected. More companies involved in Portfolio B allow decrease of weights concentration. The weighted average return is $9.1 \%$, mean return is in the range of $11.1 \%$. The average risk which is measured from 2005-2014 captured from the formula constructed above is $2.45 \%$.

Table 3 shows risk-return characteristics of manufacturers in Portfolio B on the yearly basis.

Table 3

Risk-return characteristics of Portfolio B

\begin{tabular}{|c|c|c|c|c|}
\hline Year & Mean ROE & Weighted ROE & $\begin{array}{c}\text { Standard deviation of } \\
\text { winsorised (95\%) ROE }\end{array}$ & $\sigma$ \\
\hline 2005 & $12.5 \%$ & $13.3 \%$ & $18.8 \%$ & $3.87 \%$ \\
\hline 2006 & $12.5 \%$ & $8.6 \%$ & $16.8 \%$ & $3.32 \%$ \\
\hline 2007 & $13.4 \%$ & $13.7 \%$ & $14.0 \%$ & $2.68 \%$ \\
\hline 2008 & $10.5 \%$ & $7.7 \%$ & $12.4 \%$ & $2.59 \%$ \\
\hline 2009 & $4.7 \%$ & $2.2 \%$ & $18.5 \%$ & $2.66 \%$ \\
\hline 2010 & $8.6 \%$ & $6.1 \%$ & $13.6 \%$ & $1.87 \%$ \\
\hline 2011 & $10.9 \%$ & $10.9 \%$ & $13.6 \%$ & $1.79 \%$ \\
\hline 2012 & $11.8 \%$ & $11.8 \%$ & $14.5 \%$ & $1.73 \%$ \\
\hline 2013 & $11.5 \%$ & $3.0 \%$ & $17.2 \%$ & $2.02 \%$ \\
\hline 2014 & $14.4 \%$ & $13.5 \%$ & $14.2 \%$ & $1.97 \%$ \\
\hline
\end{tabular}

Source: Authors' result

The average correlation coefficient of Portfolio B is 0.032. Portfolio B contains 1038 combinations, $596(57 \%)$ are positive. The highest negative correlation coefficient is between AGC Automotive Czech a.s and Gumotex a.s $(r=-0.8)$ The highest positive correlation coefficient is realized within BOS Automotive Product CZ s.r.o. and Brano Group A.S $(r=0.91)$. Compared to Portfolio A, the average correlation coefficient is lower, the portfolio of suppliers is a little more diversified.

Lines in Figure 2 represent development in mean return, the weighted average return and the standard deviation of returns in Portfolio B. 


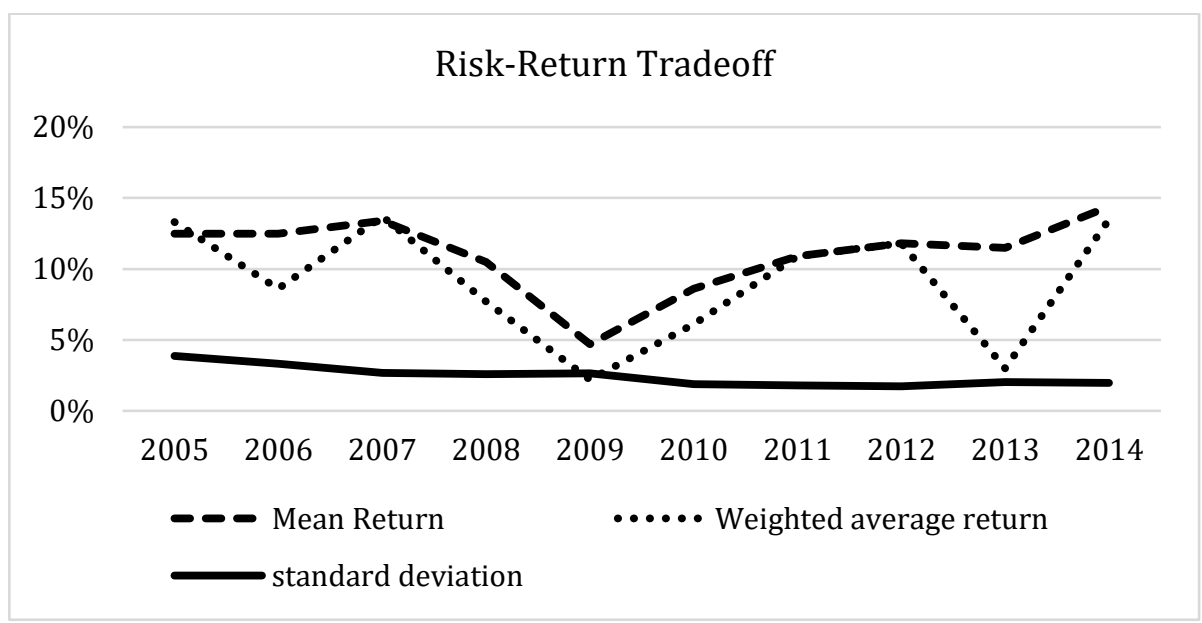

Figure 2. Risk-return tradeoff in Portfolio B

Source: Authors' result.

In the period of 2005-2014 (except 2009), investors in Portfolio B have been compensated for the risk, since the weighted average return has been higher than the risk level, measured by the standard deviation of the returns $(\sigma)$.

\subsection{Portfolio $C$ (auto suppliers and auto manufacturers) analysis}

The same methodological approach has been used to measure risk level of 49 companies that operate as suppliers and manufacturers in the Czech automotive industry, named as Portfolio C. The results of the study show risk-return results when the number of companies in the portfolio is enlarged. The weighted average return for the portfolio $\mathrm{C}$ is $13.1 \%$, mean return of the Portfolio $\mathrm{C}$ is $15.9 \%$. The average risk of Portfolio C is $5.6 \%$.

Table 4 shows risk-return characteristics of manufacturers in Portfolio $\mathrm{C}$ on the yearly basis.

Table 4

Risk-return characteristics of Portfolio C

\begin{tabular}{|c|c|c|c|c|}
\hline Year & Mean ROE & Weighted ROE & $\begin{array}{c}\text { Standard deviation of } \\
\text { winsorised }(95 \%) \text { ROE }\end{array}$ & $\sigma$ \\
\hline 2005 & $14.6 \%$ & $15.2 \%$ & $19.0 \%$ & $5 \%$ \\
\hline 2006 & $15.8 \%$ & $13.9 \%$ & $16.9 \%$ & $4.8 \%$ \\
\hline 2007 & $17.8 \%$ & $18.1 \%$ & $15.1 \%$ & $4.7 \%$ \\
\hline 2008 & $10.8 \%$ & $8.1 \%$ & $15.1 \%$ & $5.7 \%$ \\
\hline 2009 & $4.0 \%$ & $2.1 \%$ & $18.3 \%$ & $5.9 \%$ \\
\hline 2010 & $10.9 \%$ & $10.2 \%$ & $12.5 \%$ & $5.6 \%$ \\
\hline 2011 & $17.1 \%$ & $16.8 \%$ & $14.5 \%$ & $5.9 \%$ \\
\hline 2012 & $17.5 \%$ & $17.4 \%$ & $15.4 \%$ & $5.9 \%$ \\
\hline 2013 & $14.5 \%$ & $11.1 \%$ & $15.9 \%$ & $6.4 \%$ \\
\hline 2014 & $18.8 \%$ & $18.4 \%$ & $15.9 \%$ & $6.5 \%$ \\
\hline
\end{tabular}

Source: Authors' result

The average correlation in the Portfolio C is 0.076. Portfolio C contains 1083 combinations, 628 $(58 \%)$ of them are positive. The highest negative correlation is within AGC Automotive Czech a.s. and 
Gumotex a.s. $(r=-0.8)$ and the highest positive correlations between BOS Automotive Product CZ s.r.o. and Brano Group a.s. $(r=0.9)$ from the portfolio B.

Portfolio $\mathrm{C}$ is also not well diversified. Compared to the portfolio $\mathrm{A}$, the average correlation coefficient is lower, compared to the portfolio $B$, the average correlation coefficient is higher. Portfolio of suppliers and manufacturers is a little more diversified than portfolio of manufacturers, but less than portfolio of suppliers.

Lines in Figure 3 represent development in mean return, the weighted average return and the standard deviation of returns in Portfolio C.

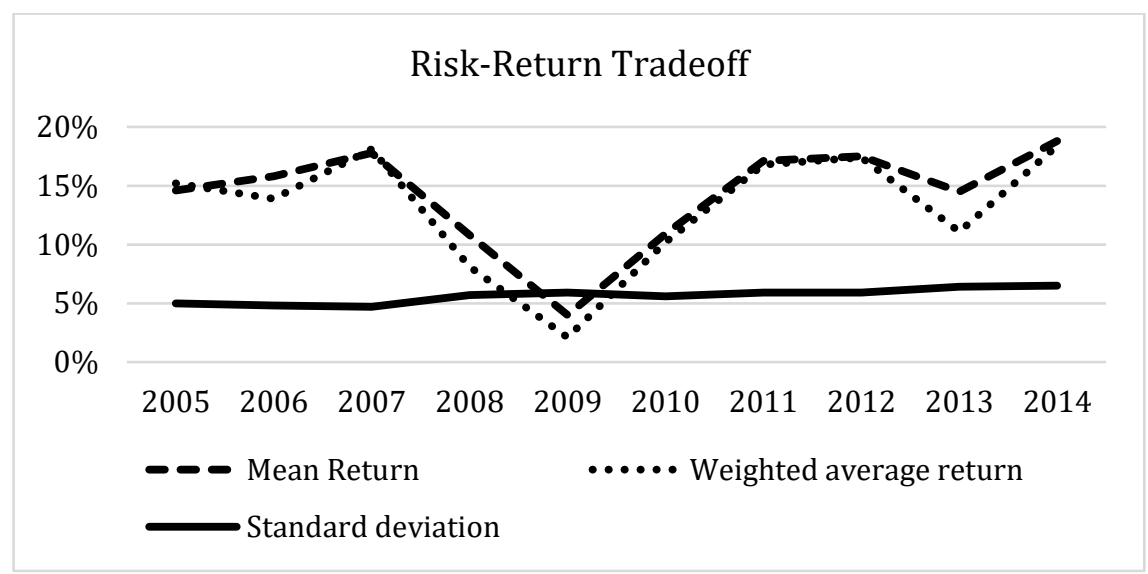

Figure 3. Risk-return tradeoff in Portfolio C

Source: Authors' results.

In the period of 2005-2014 (except 2009), investors in Portfolio C have been compensated for the risk, since the weighted average return has been higher than the risk level, measured by the standard deviation of the returns $(\sigma)$.

\subsection{Summary of portfolios' analysis results}

Summary of results are shown in Table 5. Returns are the highest for manufacturers in Portfolio A, the lowest for suppliers in Portfolio B. Return volatility as expected is the highest in Portfolio A, the lowest in Portfolio B.

Risk-return tradeoffs in Portfolio A, B and C

\begin{tabular}{|l|c|c|c|}
\hline & Portfolio A & Portfolio B & Portfolio C \\
\hline Return (weighted ROE) & $16 \%$ & $9.1 \%$ & $13.1 \%$ \\
\hline Risk $(\sigma)$ & $6.3 \%$ & $2.45 \%$ & $5.6 \%$ \\
\hline Return/Risk & 2.54 & 3.71 & 2.34 \\
\hline
\end{tabular}

Source: Authors' result

Portfolio A has the highest return and highest risk. Diversification and Return to Risk of Portfolio B is the higher in comparison with Portfolio A and C.

Risk level declined when we joined manufacturers and suppliers in Portfolio $\mathrm{C}$ in comparison with risk of manufacturers in Portfolio A. The reason stands in the fact that involvement of 37 more companies in the portfolio $\mathrm{C}$ has reduced the concentration of weights of manufacturers. However, the lowest risk is 
evident in Portfolio B (only suppliers) and Portfolio B is the best for risk-return tradeoff. The lowest return in comparison with risk was achieved by investment to the portfolio with manufacturers and suppliers.

Table 2 and Table 3 (returns measured by the weighted average of ROE) and Figure 4 (returns measured by the weighted average of ROE and ROA) confirm that auto suppliers in the Czech automotive industry were underperforming from 2005 till 2014 compared to auto manufacturers.

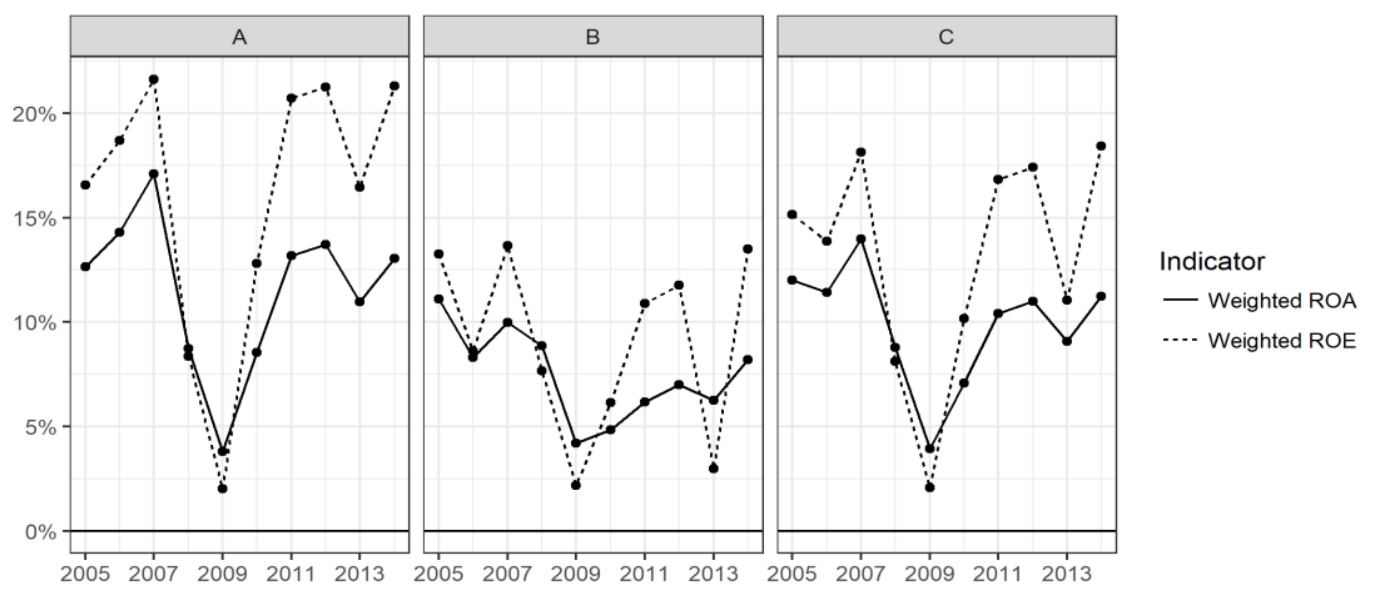

Figure 4. Development of ROE and ROA in Portfolio A, B and C in the period of 2005-2014 Source: Authors' results.

\section{CONCLUSION}

Portfolio management still remains as a science that does not give clear answers on the portfolio construction. Arranging a portfolio that would generate excess return on the investments, seems to be more an art than a science. The results show that the rising number of companies from 10 to 37 reduce the risk level, when we move from Portfolio A to Portfolio B. In contrast, when we move from Portfolio B (37 companies) to the Portfolio C (47 companies), risk level has increased. In spite that the number of securities augmented in Portfolio $\mathrm{C}$, the average correlation coefficient went up. We can conclude that investing in Portfolio C (auto suppliers and manufacturers) delivers lower risk than investing in Portfolio A (auto manufacturers) but higher risk than in the Portfolio B (auto suppliers). Which portfolio investors would choose, it depends on their risk profile. Portfolio B offers the lowest risk and also lowest returns, but the highest risk-return tradeoff.

According the results, it is clear that investments in the same sector cannot perfectly diversify risk, but there is an evidence, that it is possible to look for increasing risk-return tradeoffs creating different portfolios. As we demonstrated, the investments to auto suppliers operating in the Czech Republic during the period of 2005-2014 could create higher wealth in comparison with investments to auto manufacturers, even returns of manufacturers in the portfolio achieved higher level. The lowest wealth in comparison with risk was achieved by investment to the portfolio of manufacturers and suppliers taken together.

The world economic downturn of the financial crisis hardly affected automotive industries around the world. It is clear from our results that the Czech automotive industry was affected from the last financial crisis - returns declined rapidly. The automotive industry is very sensitive to the business cycles. Further studies might identify, if the decline of returns during and after the crisis was driven also by local factors or influenced only from the world economic distress. The stock market crash of 1987, the Asian financial crisis of 1997 and the US financial and economic downturns of 2007 demonstrated that financial markets deliver 
the first symptoms of the sick economy. Financial globalization reflected, through highly correlated stock markets, narrowed room for international portfolio diversification.

The returns in the same industry might not be a gainful target for the investor, who tends to find securities that are negatively correlated. A systematic shocks, that might occur, will affect identically most of the assets in the portfolio.

\section{ACKNOWLEDGEMENT}

Authors are grateful for the support provided by the Czech Science Foundation, project No. 1625536S: "Methodology of Developing a Predictive Model of Sector and Company Performance in the Macroeconomic Context".

\section{REFERENCES}

Alexander, C., \&Dimitriu, A. (2005). Indexing and statistical arbitrage. The Journal of Porffolio Management, 31(2), 50-63.

Behr, P., Guettler, A., \&Miebs, F. (2013). On portfolio optimization: Imposing the right constraints. Journal of Banking \& Finance, 37(4), 1232-1242.

Bertero, E., \& Mayer, C. (1990). Structure and performance: Global interdependence of stock markets around the crash of October 1987. European Economic Review, 34(6), 1155-1180.

Bird, R., \& Tippett, M. (1986). Note - Naive Diversification and Portfolio Risk - A Note. Management Science, 32(2), 244-251.

Brands, S., \& Gallagher, D. R. (2005). Portfolio selection, diversification and fund-of-funds: a note. Accounting \& Finance, 45(2), 185-197.

Brealey, R., Myers, S. C., \& Marcus, A. J. (2007). Fundamentals of Corporate Finance. Mc Graw Hill, New York.

Butler, K. C., \& Joaquin, D. C. (2002). Are the gains from international portfolio diversification exaggerated? The influence of downside risk in bear markets. Journal of International Money and Finance, 21(7), 981-1011.

Chen, M. H. (2003). Risk and return: CAPM and CCAPM. The Quarterly Review of Economics and Finance, 43(2), 369-393.

Cleary, S., \& Copp, D. (1999). Diversification with Canadian stocks: How much is enough. Canadian Investment Review, 12(3), 7-16.

DeMiguel, V., Martin-Utrera, A., \& Nogales, F. J. (2013). Size matters: Optimal calibration of shrinkage estimators for portfolio selection. Journal of Banking \& Finance, 37(8), 3018-3034.

Drake, P.P. and J.F. Frank 2010. The Basics of Finance. New Jersey: John Wiley \& Sons, Inc

Dwyer, G. and Hafer, R. (1988), “Are national stock markets linked?”, Federal Reserve Bank of St. Louis Review, Vol 70 , pp. 3-14

Domian, D. L., Louton, D. A., \& Racine, M. D. (2007). Diversification in portfolios of individual stocks: 100 stocks are not enough. Financial Review, 42(4), 557-570.

Eun, C. S., \& Shim, S. (1989). International transmission of stock marketmovements. Journal of financial and quantitative Analysis, 24(02), 241-256.

Evans, J. L., \& Archer, S. H. (1968). Diversification and the reduction of dispersion: an empirical analysis. The Journal of Finance, 23(5), 761-767.

Fama, Eugene F. (1968a). Risk, Return and Equilibrium. Chicago: Center for Mathematical Studies in Business and Economics, University of Chicago. Report No. 6831.

Fama, Eugene F. (1968b). Risk, Return, and Equilibrium: Some Clarifying Comments. Journal of Finance, 23, 29-40.

Fernandez, P. (2015). CAPM: an absurd model. Business Valuation Review, 34(1), 4-23.

Jeon, B. N., \& Vonfurstenberg, G. M. (1990). Growing international co-movement in stock-price indexes. Quarterly Review of Economics and Business, 30(3), 15-30.

Jennings, E. H. (1971). An empirical analysis of some aspects of common stock diversification. Journal of Financial and Quantitative Analysis, 797-813.

Johnson, K. H., \& Donald, S. S. (1974). A note on diversification and the reduction of dispersion. Journal of Financial Economics, 1, 365-372. 
Khan, T. A. (2011). Co-integration of international stock markets: An investigation of diversification opportunities. Undergraduate Economic Review, 8(1), 7.

Kozelsky, T., \& Novák, R. (2015). Automotive Industry: Future Trends. EU Office ČS.

Markowitz, H. (1952). Portfolio selection. The Journal of Finance, 7(1), 77-91.

Markowitz, H. (1959). Portfolio Selection, Efficient Diversification of Investments. J. Wiley.

Maxton, G. P., \& Wormald, J. (2004). Time for a Model Change: Re-engineering the Global Automotive Industry. Cambridge University Press.

Medo, M., Yeung, C. H., \& Zhang, Y. C. (2009). How to quantify the influence of correlations on investment diversification. International Review of Financial Analysis, 18(1), 34-39.

Mohamad, S., Hassan, T., \& Muhamad S. Z. (2006). Diversification across economic sectors and implication on portfolio investments in Malaysia. International Journal of Economics and Management, 1(1), 155-172.

Nieuwenhuis, P., \& Wells, P. (eds.) (2015). The Global Automotive Industry. Chichester, UK: Wiley.

Olibe, K. O., Michello, F. A., \& Thorne, J. (2008). Systematic risk and international diversification: An empirical perspective. International Review of Financial Analysis, 17(4), 681-698.

Observations of economic complexity (OEC). (2016). Retrieved from http://atlas.media.mit.edu/en/ profile/country/cze/

Ray, C. (2010). Extreme risk management: revolutionary approaches to evaluating and measuring risk. McGraw-Hill Education.

Sentana, E. (2004). Factor representing portfolios in large asset markets. Journal of Econometrics, 119(2), 257-289.

Tang, G. Y. N. (2004). How efficient is naive portfolio diversification? An educational note. The International Journal of Management Science, 32(2), 155-160.

Soros, G. (2003). The Alchemy of Finance. John Wiley \& Sons.

Sharpe, W. F. (1964). Capital asset prices: A theory of market equilibrium under conditions of risk. The Journal of Finance, 19(3), 425-442.

Shukla, R. (2004). The value of active portfolio management. Journal of Economics and Business, 56(4), 331-346.

Statman, M. (1987). How many stocks make a diversified portfolio? Journal of Financial and Quantitative Analysis, 22(03), 353-363.

Surz, R. J., \& Price, M. (2000). The truth about diversification by the numbers. The Journal of Investing, 9(4), 93-95.

Tang, G. Y. (2004). How efficient is naive portfolio diversification? An educational note. Omega, 32(2), 155-160.

Tofallis, C. (2008). Investment volatility: A critique of standard beta estimation and a simple way forward. European Journal of Operational Research, 187(3), 1358-1367.

Tola, V., Fabrizio, L., Mauro, G. \& Rosario, N.M. (2008). Cluster analysis for portfolio optimization. Journal of Economic Dynamics and Control, 32(1), 235 - 258.

Van Biesebroeck, J., \& Sturgeon, T. J. (2010). Effects of the 2008-09 crisis on the automotive industry in developing countries: a global value chain perspective. Global Value Chains in a Postcrisis World, Washington, DC: The World Bank, 209-244. 